\title{
KETEGARAN UPAH NOMINAL UNTUK TURUN: KASUS UPAH NOMINAL PEKERJA PRODUKSI DI BAWAH MANDOR PADA INDUSTRI BESAR DAN SEDANG MAKANAN JADI, BAHAN PAKAIAN, KARET, DAN PLASTIK
}

\author{
Joko Susanto \\ Fakultas Ekonomi Universitas Pembangunan Nasional "Veteran" Yogyakarta \\ Jalan SWK 104 (Lingkar Utara) Condongcatur 55283 Telp.: +62274486733 \\ E-mail: jsusanto72@yahoo.co.id
}

\begin{abstract}
This aim of the research is to test whether the decreasing productivity of the workers results in decreasing of the nominal wage of the production worker under the supervisor. Statistical data of BPS was used in this research. The research data is consist of the nominal base and over time wage of the production worker under the supervisor, productivity of workers, and capital intensity. Furthermore, this research used regression analysis with OLS estimation method. This regression analysis was based on the dynamic panel data model. Finally, this study used redundant coefficient test to reduce several insignificant regression parameters in order to get a parsimony model. The results of the research as follow: (1). the decreasing productivity of the workers does not result in decreasing the nominal base wages of the production workers under the supervisor. (2). the decreasing productivity of the workers results in decreasing of the over time wages of the production workers under the supervisor.
\end{abstract}

Keywords: ketegaran upah, upah nominal, produktivitas, industry

\section{PENDAHULUAN}

Krisis moneter yang terjadi pada pertengahan tahun 1997 ditandai dengan fluktuasi dan kenaikan nilai tukar dollar Amerika Serikat (AS). Fluktuasi nilai tukar dollar AS menyebabkan perusahaan mengalami kesulitan dalam penganggaran. Kebutuhan dana untuk kegiatan operasional seringkali lebih besar daripada dana yang telah dianggarkan perusahaan. Hal ini mengganggu kelancaran kegiatan operasional perusahaan. Sementara itu, kenaikan nilai tukar dollar AS menyebabkan harga barang dan jasa impor naik dengan pesat. Di antara barang impor yang harganya meningkat adalah barang modal, bahan baku dan bahan penolong yang merupakan input bagi sektor industri manufaktur. Kenaikan harga bahan baku impor akibat kenaikan nilai tukar dollar AS berdampak pada kenaikan biaya produksi. Selanjutnya, ketidaklancaran kegiatan operasional dan kenaikan biaya produksi menyebabkan perusahaan mengalami kerugian. Agar perusahaan tidak mengalami kerugian, pengusaha menaikkan harga outputnya (Tambunan, 2000: 99). Kenaikan harga output akan menurunkan jumlah output yang diminta. 
Penurunan jumlah output yang diminta mengakibatkan tingkat produksi industri berada di bawah tingkat produksi normal. Jumlah output berada di bawah kapasitas terpasang. Penurunan realisasi produksi terhadap kapasitas terpasang berarti perusahaan memproduksi barang dalam jumlah yang lebih kecil dibandingkan dengan kapasitas yang ada. Kapasitas terpasang menjadi berlebih atau dengan kata lain terjadi kapasitas menganggur (Departemen Perindustrian, 2005: 21; Hidayat, 2005: 4).

Penurunan realisasi produksi terhadap kapasitas terpasang terjadi pada semua sub sektor industri. Dalam penelitian ini, cakupan sub sektor industri meliputi industri besar dan sedang makanan jadi, bahan pakaian, karet dan plastik. Pemilihan cakupan sub sektor industri ini berdasar pertimbangan bahwa industri-industri tersebut mengalami penurunan realisasi produksi terhadap kapasitas terpasang terutama pada tahun 1998. Di samping itu, jumlah pekerja pada kelompok industri ini relatif besar.

Penurunan realisasi produksi terhadap kapasitas terpasang mengakibatkan penurunan jumlah output yang dapat dihasilkan oleh setiap pekerja. Hal ini menunjukkan turunnya produktivitas pekerja. Penurunan produktivitas pekerja menimbulkan kesulitan dalam penentuan tingkat upah nominal. Adanya penurunan produktivitas pekerja menunjukkan penurunan sumbangan (kontribusi) pekerja dalam proses produksi. Hal ini akan menjadi alasan bagi pengusaha untuk mengurangi bagian output yang diterima pekerja. Pekerja akan menghadapi kemungkinan penurunan tingkat upah nominal.

Sebagian besar pekerja pada sektor industri merupakan pekerja produksi di bawah mandor. Kelompok ini berada pada tingkatan paling rendah sehingga rentan terhadap kemungkinan penurunan upah nominal.

Permasalahan dalam penelitian ini dirumuskan sebagai berikut; Apakah penurunan produktivitas pekerja menyebabkan penurunan upah nominal pekerja produksi di bawah mandor pada industri makanan jadi, bahan pakaian, karet dan plastik di Indonesia pada tahun 1997-2003?

Upah nominal pekerja produksi di bawah mandor terdiri dari upah pokok nominal dan tunjangan. Tunjangan ini sebagian besar berasal dari upah lembur.

Tinjauan pustaka dalam penelitian ini sebagai berikut:

Upah nominal merupakan hasil negosiasi/ tawar menawar antara pekerja dan pengusaha. Prasyarat dasar bagi peningkatan upah nominal adalah produktivitas pekerja. Produktivitas pekerja merupakan acuan pokok dalam penentuan tingkat upah nominal. Hal ini berimplikasi bahwa negosiasi upah nominal akan berkaitan dengan produktivitas pekerja (Mamman dkk, 1996: 112).

Penurunan produktivitas pekerja menjadikan masalah penentuan tingkat upah nominal semakin kompleks. Kemampuan perusahaan untuk memberikan balas jasa terhadap pemilik modal dan tenaga kerja berkurang. Pengusaha mengalami kesulitan untuk memberikan bagian dari output yang menjadi hak pekerja. Pekerja menghadapi kemungkinan penurunan tingkat upah nominal.

Adanya penurunan produktivitas pekerja menyebabkan kurva permintaan tenaga kerja bergeser ke kiri. Akan tetapi penurunan produktivitas pekerja tidak mengakibatkan penurunan upah nominal sebagaimana terli- 




Sumber: McConell dkk, 2003: 570

\section{Gambar 1. Ketegaran Upah Nominal untuk Turun}

hat pada gambar 1. Agar moral pekerja (partisipasi, kejujuran dan kerjasama) senantiasa tinggi, perusahaan menetapkan tingkat upah yang melebihi upah pasar (Bewley, 1998). Perusahaan menetapkan tingkat upah nominal setinggi $\mathrm{OP}_{2}$ yang melebihi tingkat upah pasar $O P_{1}$. Keseimbangan awal terjadi di titik $E_{1}$ dengan jumlah pekerja sebesar $O L_{1}$. Penurunan produktivitas pekerja menggeser kurva permintaan tenaga kerja $D_{L 1}$ ke kiri menjadi $D_{L 2}$. Keseimbangan baru terjadi di titik $E_{2}$, dengan tingkat upah nominal tetap setinggi $\mathrm{OP}_{2}$, tetapi jumlah pekerja berkurang menjadi $\mathrm{OL}_{2}$. Penurunan produktivitas pekerja direspons oleh pengusaha dengan cara mengurangi jumlah pekerja dan bukan dengan menurunkan upah nominal.

Hasil penelitian sebelumnya yaitu: Lebow dan kawan-kawan (1999) meneliti ketegaran upah untuk turun di Amerika Serikat. Hasil penelitian ini menunjukkan adanya ketegaran upah nominal untuk turun. Perusahaan dapat menghindari ketegaran upah untuk turun dengan melakukan variasi pada kompensasi pekerja. Ketegaran kom- pensasi untuk turun lebih lemah daripada ketegaran upah untuk turun.

Castellanos dan kawan-kawan (2004) menganalisis ketegaran upah nominal untuk turun di Meksiko. Penelitian ini memperoleh temuan bahwa upah nominal tegar untuk turun. Peraturan tentang upah minimum menyebabkan upah nominal tegar untuk turun. Tingkat upah nominal akan sulit untuk turun di bawah tingkat upah minimum. Hasil yang sama juga diperoleh Pedro Portugal (2006) yang menganalisis ketegaran upah nominal untuk turun di Portugal.

Hipotesis penelitian ini sebagai berikut:

1. Penurunan produktivitas pekerja tidak mengakibatkan upah pokok nominal pekerja produksi di bawah mandor mengalami penurunan.

2. Penurunan produktivitas pekerja mengakibatkan upah lembur pekerja produksi di bawah mandor mengalami penurunan.

Desain penelitian adalah seperti terlihat pada gambar 2. Penurunan jumlah output yang diminta mengakibatkan penurunan 


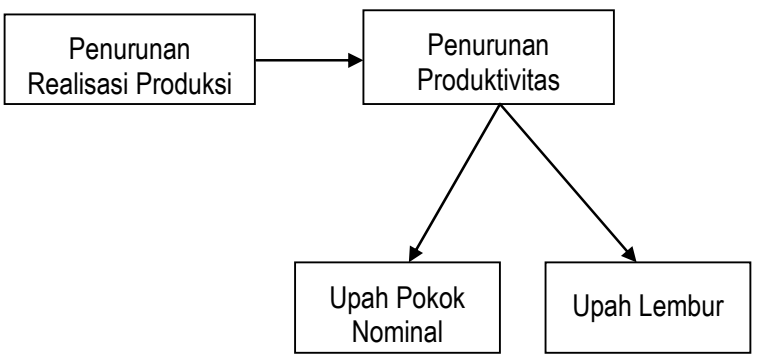

Gambar 2. Desain Penelitian

realisasi produksi. Hal tersebut akan berdampak pada penurunan produktivitas pekerja. Penurunan produktivitas pekerja menunjukkan penurunan sumbangan (kontribusi) pekerja, termasuk pekerja produksi di bawah mandor. Pekerja ini menghadapi kemungkinan penurunan tingkat upah nominal.

\section{METODE PENELITIAN}

\section{Data dan Sumber Data}

Penelitian ini menggunakan data dari Badan Pusat Statistik (BPS). Data yang digunakan mencakup upah pokok dan lembur, produktivitas pekerja, dan intensitas modal. Data upah pokok dan lembur pekerja produksi di bawah mandor merupakan data mentah dari BPS yang tidak dipublikasikan, sedangkan data produktivitas dan intensitas modal berasal dari publikasi "Statistik Industri" BPS.

\section{Variabel Operasional}

Berikut akan dijelaskan definisi operasional dari masing-masing variabel.

1. Upah pokok nominal adalah upah pokok nominal yang diterima setiap pekerja produksi di bawah mandor dalam setiap bulannya. Satuan yang digunakan adalah ribu rupiah per pekerja.

2. Upah lembur adalah penerimaan uang lembur oleh setiap pekerja produksi di bawah mandor dalam setiap bulannya. Satuan yang digunakan adalah ribu rupiah per pekerja.

3. Produktivitas pekerja adalah nilai barang yang dihasilkan dibagi dengan jumlah pekerja. Satuan produktivitas pekerja adalah juta rupiah per pekerja.

4. Intensitas modal adalah rasio modal terhadap jumlah pekerja. Satuan intensitas modal adalah juta rupiah per pekerja.

Variabel upah pokok nominal dan upah lembur dinyatakan dalam harga nominal, sedangkan variabel produktivitas pekerja dan intensitas modal menggunakan nilai riil. Penggunaan harga nominal pada variabel upah pokok nominal dan upah lembur dikarenakan penelitian ini mengkaji ketegaran upah nominal untuk turun.

\section{Alat Analisis}

Penyusunan model empirik dilakukan dengan cara menghubungkan tingkat upah dengan variabel-variabel sumber laba dan tingkat 
upah periode sebelumnya (Mahmood, 1999). Variabel sumber laba meliputi produktivitas pekerja, dan intensitas modal. Melalui pendekatan ini, dapat dibangun persamaan berikut.

$$
w_{t}=f\left(y_{t}, k_{t}, w_{t-1}\right)
$$

$w$ adalah upah nominal

$y_{t}$ adalah produktivitas pekerja

$k_{t}$ adalah intensitas modal

$w_{t-1}$ adalah tingkat upah periode sebelumnya

Persamaan (2) dapat dituliskan kembali sebagai

$$
w_{t}=b_{0}+b_{1} Y_{t}+b_{2} k_{t}+b_{3} w_{t-1}+u
$$

Oleh karena observasi meliputi beberapa industri selama beberapa periode, maka estimasi dilakukan berdasar data panel. Penggunaan data panel mempunyai keunggulan dibandingkan dengan data runtun waktu atau belah silang murni. Penggunaan data panel akan menaikkan derajat kebebasan dan mengurangi kolinieritas di antara variabel penjelas sehingga menghasilkan koefisien estimasi yang efisien. Data panel juga memungkinkan untuk mengontrol heterogenitas individual dan lebih mampu mengamati dinamika penyesuaian (Baltagi, 2000, 5).

Berdasar persamaan (2), dapat dibangun model regresi data panel melalui reduksi mulai dari lag terpanjang sehingga diperoleh hasil estimasi yang paling sederhana (parsimonious regression). Untuk menguji ketegaran upah pokok nominal dan upah lembur, maka dimasukkan variabel dummy (DUM) ke dalam persamaan regresi dinamik sehingga diperoleh persamaan

$$
\begin{aligned}
& d W_{i t}=\alpha_{i}+\sum_{j=0}^{k} \beta_{i j} d Y_{i t-j}+\sum_{j=1}^{k} \gamma_{i j} d k_{i t-j}+ \\
& \sum_{j=1}^{k} \omega_{i j} W_{i t-j}+\lambda_{i} E C T_{t-1}+\sum_{j=0}^{k} \rho_{i} D U M d Y_{i t-j}
\end{aligned}
$$

Keterangan:

$W_{1 i t}$ merupakan variabel upah pokok nominal

$W_{2 i t}$ merupakan variabel upah lembur

$D U M=1$ jika produktivitas pekerja turun $\left(\mathrm{dY} \mathrm{it}_{\mathrm{it}}<0\right)$

$D U M=0$ jika produktivitas pekerja tidak turun $\left(d Y_{\text {it }} \geq 0\right)$

\section{HASIL PENELITIAN DAN PEMBAHASAN}

\section{Analisis Kuantitatif}

Salah satu konsep penting dalam teori ekonometri adalah anggapan stasioneritas variabelvariabel yang diestimasi. Data yang stasioner memiliki kecenderungan untuk kembali menuju nilai rata-ratanya. Sementara itu, data yang non-stasioner tidak memiliki kecenderungan untuk kembali menuju nilai rata-ratanya. Untuk mengetahui apakah variabel yang diobservasi tidak stasioner atau stasioner digunakan uji akar-akar unit. Pengujian akar-akar unit dalam penelitian ini menggunakan model Levin dan Lin (1993). Pengujian ini berasumsi bahwa terdapat unit roots yang bersifat umum untuk seluruh unit belah silang.

Hasil uji akar-akar unit model Levin dan Lin menunjukkan bahwa variabel-variabel dalam model tidak stasioner pada level sebagaimana terlihat pada tabel 1. Pengujian akar-akar unit terhadap variabel $W_{1}, Y$ dan $K L$ pada level menunjukkan nilai $t$-statistik 
Tabel 1. Hasil Uji Akar-Akar Unit dan Derajat Integrasi berdasar Model Levin dan Lin

\begin{tabular}{ccccc}
\hline Variabel & \multicolumn{2}{c}{ Aras (level) } & \multicolumn{2}{c}{ Differensi Pertama } \\
\hline & $t$-statistik & Nilai kritis & $t$-statistik & Nilai Kritis \\
$W_{1}$ & 1,782 & $-2,09$ & $-4,214)^{*}$ & $-2,09$ \\
$W_{2}$ & $-1,166$ & $-2,09$ & $-2,174)^{*}$ & $-2,09$ \\
$Y$ & 5,177 & $-2,09$ & $-6,392)^{*}$ & $-2,09$ \\
$K L$ & 2,060 & $-2,09$ & $-3,147)^{*}$ & $-2,09$ \\
\hline
\end{tabular}

*) menunjukkan signifikansi pada tingkat ( $\alpha=5 \%$ )

Sumber: Lampiran 1

yang bertanda positif. Hasil pengujian ini berlawanan dengan kaidah uji akar-akar unit dikarenakan nilai $\rho>1$. Dalam kasus ini, proses autoregressive bersifat eksplosif. Nilai variabel-variabel $W_{1}, W_{3}$, dan $Y$ cenderung berkembang tanpa batas (Patterson, 2000: 209).

Variabel-variabel dalam model tidak stasioner pada level. Untuk itu, pengujian dilanjutkan dengan uji derajat integrasi guna mengetahui pada derajat integrasi ke berapa variabel-variabel tersebut stasioner. Hasil uji derajat integrasi menunjukkan bahwa seluruh variabel stasioner pada derajat integrasi pertama.

Tahapan selanjutnya setelah pengujian akar-akar unit dan derajat integrasi adalah uji kointegrasi. Melalui uji kointegrasi akan diketahui apakah suatu set variabel berkointegrasi ataukah tidak. Pendekatan ini berkaitan dengan kemungkinan adanya hubungan keseimbangan jangka panjang antar variabel ekonomi seperti yang dikehendaki dalam teori ekonomi. Pengujian kointegrasi mengacu pada model pengujian yang dikembangkan Pedroni (1999).

Hasil pengujian kointegrasi terlihat seperti pada tabel 2. Berdasarkan tabel 2 terlihat adanya penolakan terhadap hipotesis $\mathrm{H}_{0}$ yang menyatakan tidak adanya kointegrasi untuk model panel Philips-Perron statistik dan panel ADF statistik. Dengan demikian dapat dikatakan bahwa residual regresi kointegrasi adalah stasioner $I(0)$, sehingga variabel-variabel dalam model akan berkointegrasi atau memiliki hubungan keseimbangan jangka panjang.

Tabel 2. Hasil Uji Kointegrasi Pedroni

\begin{tabular}{clccr}
\hline Nomor & Panel Statistik & $\begin{array}{c}\text { Upah Pokok Nominal } \\
\text { Pekerja Produksi }\end{array}$ & $\begin{array}{c}\text { Upah Pokok Pekerja } \\
\text { Non- Produksi }\end{array}$ & $\begin{array}{c}\text { Nilai Kritis } \\
\text { Pedroni }\end{array}$ \\
\hline 1. & Panel V-stat & $-0,99$ & $-1,21$ & 6,98 \\
2. & Panel Rho-stat & 1,36 & 0,62 & $-6,39$ \\
3. & Panel PP-stat & $-3,13)^{*}$ & $-4,60)^{*}$ & $-1,66$ \\
4. & Panel ADF-stat & $-3,06)^{*}$ & $-6,43)^{*}$ & $-1,66$ \\
5. & Panel Rho-stat & 2,07 & 1,65 & $-9,89$ \\
6. & Panel PP-stat & $-4,55)^{*}$ & $-4,05)^{*}$ & $-1,99$ \\
7 & Panel ADF-stat & $-3,23)^{*}$ & $-18,14)^{*}$ & $-1,99$ \\
\hline
\end{tabular}

$\left.{ }^{*}\right)$ signifikan pada ( $a=5 \%$ )

Sumber: Lampiran 2 
Tabel 3. Hasil Penentuan Panjang Lag Berdasar Kriteria Akaike

\begin{tabular}{cccc}
\hline Panjang Lag & Model Upah Pokok Nominal & Model Upah Lembur \\
\hline 1 & 1 & 47,04 & 41,78 \\
1 & 2 & 40,46 & 41,02 \\
1 & 3 & $38,29)^{*}$ & $40,39)^{*}$ \\
2 & 2 & 42,39 & 43,63 \\
2 & 3 & 40,38 & 41,43 \\
\hline
\end{tabular}

*) panjang lag optimum

Sumber: Lampiran 3

Tabel 4. Hasil Pengujian F Terkendala

\begin{tabular}{lccll}
\hline \multicolumn{1}{c}{ Model } & F-hitung & $\begin{array}{c}\text { F-tabel } \\
\alpha=5 \%\end{array}$ & Keterangan & \multicolumn{1}{c}{ Kesimpulan } \\
& & & \\
\hline Upah Pokok Nominal & 5,140 & 3,41 & F-hitung signifikan & Intercept berbeda-beda \\
Upah Lembur & 1,889 & 3,41 & F-hitung tidak signifikan & Intercept sama \\
\hline
\end{tabular}

Selanjutnya untuk menghindari kesalahan spesifikasi model akibat lag terlalu pendek dan pengurangan derajat kebebasan akibat lag terlalu panjang, maka perlu ditentukan panjang lag yang tepat. Penentuan panjang lag dalam penelitian ini menggunakan Akaike. Hal ini dikarenakan kriteria Akaike lebih unggul dibandingkan kriteria lain (Liew, 2004 : 1-9). Nilai kriteria Akaike yang lebih kecil, menunjukkan model yang lebih baik. Berdasar kriteria Akaike, panjang lag optimum adalah 3 tahun seperti terlihat pada tabel 3.

\section{Estimasi Model Panel ECM}

Model koreksi kesalahan (ECM) memiliki keseimbangan yang tetap dalam jangka panjang antara variabel-variabel ekonomi. Apabila dalam jangka pendek terdapat ketidakseimbangan, maka ECM akan melakukan koreksi pada periode berikutnya. Mekanisme koreksi kesalahan merupakan penyelaras perilaku jangka pendek dan jangka panjang.
Melalui mekanisme ini masalah regresi lancung dapat dihindari dengan penggunaan variabel-variabel difference, tanpa menghilangkan informasi jangka panjang akibat penggunaan data difference.

Selanjutnya untuk memilih model yang baik apakah dengan intercept sama ataukah intercept berbeda-beda untuk tiap unit belah silang perlu dilakukan pengujian $F$ terkendala (Restricted F test). Hasil uji $F$ terkendala terlihat seperti pada tabel 4. Nilai Fhitung pada model upah pokok nominal melebihi nilai $F$ - tabel pada signifikansi $(\alpha=$ $5 \%$ ), sehingga model upah pokok nominal yang baik adalah model dengan intercept berbeda-beda untuk setiap unit belah silang. Sebaliknya untuk model upah lembur, nilai $F$ - hitung lebih kecil daripada nilai $F$ - tabel pada signifikansi $(\alpha=5 \%)$. Model yang baik untuk persamaan upah lembur adalah model common intercept. 


\section{Hasil Estimasi}

Hasil estimasi diperoleh melalui estimasi terhadap persamaan (3). Selanjutnya dilakukan reduksi terhadap paramater-paramater yang tidak signifikan dengan mengaplikasikan uji redundant coefficient sehingga diperoleh hasil estimasi sederhana. Hasil pengujian redundant coefficient pada Tabel 7 menunjukkan nilai $F$-hitung lebih rendah dari $F$-tabel sehingga tidak signifikan. Hal ini berarti beberapa koefisien regresi memang tidak signifikan. Dengan demikian model yang dipergunakan sebagai dasar analisis adalah model dengan reduksi. Berikut ini hasil estimasi kedua model dan uji redundant coefficient.

\section{Pengujian Hipotesis}

\section{Analisis Kualitatif}

a. Dampak penurunan produktivitas pekerja terhadap upah pokok nominal pekerja produksi di bawah mandor

Pada model upah pokok nominal pekerja produksi di bawah mandor (tabel 5), nilai koefisien error correction term $\left(E C T_{1}\right)$ sebesar -0,001. Ini berarti sebesar 0,1 persen ketidakseimbangan pada periode $t-1$ dikoreksi pada periode $t$. Besarnya angka koefisien error correction term $\left(E C T_{1}\right)$ menunjukkan bahwa kecepatan penyesuaian upah nominal menuju ke kondisi keseimbangan relatif lambat.

Variabel-variabel yang diestimasi berpengaruh signifikan terhadap upah pokok nominal pekerja produksi di bawah mandor. Variabel $D W_{11}$ dan $D W_{13}$ yang bertanda positif dan signifikan menunjukkan bahwa penentuan upah pokok nominal pada suatu periode akan mempertimbangkan upah pokok nominal periode sebelumnya. Demikian pula dengan variabel intensitas modal $(D K L)$ juga berpengaruh positif terhadap upah pokok nominal pekerja produksi di bawah mandor.

Dampak penurunan produktivitas pekerja terhadap upah pokok nominal pekerja produksi di bawah mandor ditunjukkan oleh penjumlahan koefisien produktivitas $\left(D Y_{1}\right)$ yang bertanda positif dan variabel dummy (DUMDY 1 ) yang bertanda negatif. Penurunan produktivitas pekerja sebesar 1 juta rupiah per pekerja, dalam jangka pendek akan

\section{Tabel 5. Hasil Estimasi Jangka Pendek Model Upah Pokok Nominal (Fixed Effects)}

\begin{tabular}{clccc}
\hline No. & \multicolumn{1}{c}{ Variabel } & Koefisien & t-statistik & $t$-tabel $(\alpha=5 \%)$ \\
\hline 1. & C & 342,047 & 5,629 & $1,771)^{*}$ \\
2. & DW11 & 0,001 & 4,348 & $1,771)^{*}$ \\
3. & DW13 & 0,976 & 3,679 & $1,771)^{\star}$ \\
4. & DY1 & 9,316 & 6,514 & $1,771)^{*}$ \\
5. & DUMDY1 & $-6,198$ & $-3,229$ & $-1,771)^{\star}$ \\
6. & DKL & 5,312 & 4,519 & $1,771)^{*}$ \\
7. & ECT1 & $-0,001$ & $-9,073$ & $-1,771)^{*}$ \\
\hline
\end{tabular}

Variabel dependen: $D W_{1}$

Adjusted $\mathrm{R}^{2}=83,73$

*) signifikan pada ( $a=5 \%)$

Sumber: Lampiran 4 
diikuti dengan kenaikan upah pokok nominal pekerja produksi di bawah mandor sebesar 3.118 rupiah. Temuan ini mendukung hipotesis 1 yang menyatakan bahwa penurunan produktivitas pekerja tidak mengakibatkan turunnya upah pokok nominal pekerja produksi di bawah mandor. Tingkat upah pokok nominal pekerja produksi di bawah mandor tetap mengalami kenaikan walaupun pada saat bersamaan produktivitas pekerja turun. Hal ini dikarenakan adanya peraturan upah minimum. Tingkat upah minimum provinsi (UMP) senantiasa mengalami kenaikan dari tahun ke tahun. Kenaikan UMP mengakibatkan kenaikan upah pokok nominal pekerja produksi di bawah mandor. b. Dampak penurunan produktivitas pekerja terhadap upah lembur pekerja produksi di bawah mandor

Pada model upah pokok nominal pekerja produksi di bawah mandor (tabel 6), nilai koefisien error correction term $\left(E C T_{2}\right)$ sebesar -0,002. Ini berarti sebesar 0,2 persen ketidakseimbangan pada periode $t-1$ dikoreksi pada periode $t$. Besarnya angka koefisien error correction term $\left(E C T_{2}\right)$ menunjukkan bahwa kecepatan penyesuaian upah nominal menuju ke kondisi keseimbangan relatif lambat.

Variabel $D W_{22}$ dan $D K L_{1}$ tidak berpengaruh signifikan terhadap upah lembur pekerja produksi di bawah mandor. Hal ini dikarenakan kerja lembur bersifat variabel sehingga upah

Tabel 6. Hasil Estimasi Jangka Pendek Model Upah Lembur (Common Effects)

\begin{tabular}{ccrrc}
\hline No. & Variabel & \multicolumn{1}{l}{ Koefisien } & \multicolumn{1}{c}{$\boldsymbol{t}$-statistik } & $\begin{array}{c}t \text {-tabel } \\
(\mathbf{\alpha}=5 \%)\end{array}$ \\
\hline 1. & C & 186,372 & 2,914 & $1,761)^{\star}$ \\
2. & DW22 & 0,001 & 0,196 & 1,761 \\
3. & DY1 & 17,959 & 2,193 & $1,761)^{\star}$ \\
4. & DUMDY1 & $-13,869$ & $-1,531$ & $-1,761$ \\
5. & DKL1 & 0,899 & 0,151 & 1,761 \\
6. & ECT2 & $-0,002$ & $-3,209$ & $-1,761)^{\star}$ \\
\hline
\end{tabular}

Variabel dependen: $D W_{2}$

Adjusted $\mathrm{R}^{2}=44,241$

*) signifikan pada $(\alpha=5 \%)$

Sumber: Lampiran 4

Tabel 7. Hasil Pengujian Redundant Coefficient

\begin{tabular}{lccll}
\hline \multicolumn{1}{c}{ Model } & F-hitung & F-Tabel $\alpha=5 \%$ & Keterangan & Kesimpulan \\
\hline Upah pokok nominal & 18,896 & 250,543 & $\begin{array}{l}\text { F hitung tidak } \\
\text { signifikan }\end{array}$ & Model reduksi benar \\
Upah lembur & 3,413 & 5,998 & $\begin{array}{l}\text { Fhitung tidak } \\
\text { signifikan }\end{array}$ & Model reduksi benar \\
\hline
\end{tabular}

Sumber: Lampiran 4 
lembur pada suatu periode tidak bergantung pada upah lembur periode sebelumnya. Di samping itu, kerja lembur biasanya tidak dilakukan oleh seluruh pekerja sehingga faktor produksi modal senantiasa tersedia dalam jumlah yang mencukupi. Ketersediaan faktor produksi pada waktu kerja lembur mengakibatkan intensitas modal tidak berpengaruh terhadap upah lembur.

Dampak penurunan produktivitas pekerja terhadap upah lembur pekerja produksi di bawah mandor ditunjukkan oleh penjumlahan koefisien produktivitas $\left(D Y_{1}\right)$ yang bertanda positif dan variabel dummy (DUMDY $)$ yang bertanda negatif. Variabel $D U M D Y_{1}$ tidak signifikan sehingga penurunan produktivitas pekerja sebesar satu satuan mengakibatkan penurunan upah lembur pekerja produksi di bawah mandor sebesar koefisien variabel $D Y_{1}$. Penurunan produktivitas pekerja sebesar 1 juta rupiah per pekerja, dalam jangka pendek akan menurunkan upah lembur pekerja produksi di bawah mandor sebesar 17.959 rupiah. Temuan ini mendukung hipotesis 2 yang menyatakan bahwa penurunan produktivitas pekerja mengakibatkan turunnya upah lembur pekerja produksi di bawah mandor.

\section{KESIMPULAN}

Berdasar hasil analisis, maka diperoleh beberapa kesimpulan berikut.

Pertama, penurunan produktivitas pekerja tidak mengakibatkan penurunan upah pokok nominal pekerja produksi di bawah mandor turun. Upah pokok nominal pekerja produksi di bawah mandor tegar untuk turun.
Kedua, penurunan produktivitas pekerja mengakibatkan turunnya upah lembur pekerja produksi di bawah mandor. Upah lembur pekerja produksi di bawah mandor tidak tegar untuk turun.

Sedangkan saran-saran yang diajukan penulis sebagai berikut:

Pertama, karena upah pokok nominal pekerja produksi di bawah mandor tegar untuk turun, maka tingkat upah tersebut cukup ditetapkan sama atau sedikit lebih tinggi daripada Upah Minimum Provinsi (UMP) dan Kebutuhan Hidup Layak (KHL). Hal ini untuk mengantisipasi agar tidak terjadi penurunan upah di kemudian hari apabila kinerja perusahaan menurun.

Kedua, perusahaan dapat memberikan bobot cukup besar pada upah lembur dengan berdasar kinerja (laba) perusahaan. Tingkat upah lembur yang relatif tinggi tidak menjadi masalah bagi perusahaan karena kerja lembur bersifat variabel sesuai dengan kebutuhan dan kondisi perusahaan.

\section{DAFTAR PUSTAKA}

Badan Pusat Statistik, Statistik Industri Besar dan Sedang, Jakarta, beberapa edisi.

Baltagi, Badi, H., 2003. Econometric Analysis of Panel Data, John Wiley and Sons.

Bewley, T.F., 1998, "Why Not Cut Pay", European Economic Review, 42:45990.

Castellanos, S.G., Rodrigo Garcia-Verdu, and David S. Kaplan. 2004. "Nominal Wage Rigidities in Mexico: Evidence from Social Security Records" Journal of Development Economics, 75: 507533. 
Departemen Perindustrian Republik Indonesia, 2005. Kebijakan Pembangunan Industri Nasional, Jakarta.

Hidayat, Agus Syarip, 2005, "Konsumsi BBM dan Peluang Pengembangan Energi Alternatif', Inovasi, Vol.5/XVII/ November

Lebow, David, E., R.E. Saks dan B.A. Wilson, 1999, Downward Nominal Wage Rigidity, Working Paper, Federal Reserve Bank.

Levin, A dan C.F. Lin, 1993. Unit Root Test in Panel Data; New Results, Discussion Paper No.93-56, University of California San Diego.

Liew, Venus Khim-Sen, (2004). Which Lag Length Selection Criteria Should We Employ?. Economics Bulletin, 33: 1-9.

Mahmood, A, 1999. Wages, Profits and Capital Intensity: Evidence from Matched Worker-Firm Data, Working Paper, Department of Economics, Stockholm University.

Mamman, Aminu, Mohamed Sulaiman dan Alfadli Fadel, 1996. Attitude to pay Sistems: An Explanatory within and Across Culture, The International Journal of Resource Management, 7(1).

McConnel, Champbell, R., Stanley L. Brue, dan David A. Macpherson, 2003. Contemporary Labor Economics, New York: McGraw-Hill.
Patterson, Kerry, 2000. An Introduction to Applied Econometrics: A Time Series Approach, New York: Palgrave.

Pedroni, Peter, 1999. Critical Values for Cointegration Tests in Heterogeneous Panels with Multiple Regressors, Oxford Bulletin of Economics and Statistics, Special Issues, 653-670

Portugal, Pedro, 2006. "Wage Setting in the Portuguese Labor Market: A Microeconomic Approach", Economic Bulletin, 78: 89-100.

Tambunan, Tulus, 2000. "the Performance of Small Enterprises during Economic Crisis: Evidence from Indonesia", Journal of Small Business Management; 93-101. 


\section{LAMPIRAN 1}

\section{Uji Akar-akar Unit dan Derajat Integrasi}

Variabel $W_{1}$

Null Hypothesis: Unit root (common unit root process)

Date: 08/19/08 Time: 23:04

Sample: 19972005

Exogenous variables: Individual effects

Automatic selection of maximum lags

Automatic selection of lags based on AIC: 0 to 1

Newey-West bandwidth selection using Bartlett kernel

Total number of observations: 31

Cross-sections included: 4

\begin{tabular}{llc}
\hline \hline Method & & \\
\hline Levin, Lin \& Chu t* & Statistic & Prob.** $^{*}$ \\
& 1.78186 & 0.9626 \\
\hline \hline
\end{tabular}

** Probabilities are computed assuming asympotic normality

Null Hypothesis: Unit root (common unit root process)

Date: 08/19/08 Time: 23:03

Sample: 19972005

Exogenous variables: Individual effects

Automatic selection of maximum lags

Automatic selection of lags based on AIC: 0

Newey-West bandwidth selection using Bartlett kernel

Total (balanced) observations: 28

Cross-sections included: 4

\begin{tabular}{lcc} 
Method & Statistic & Prob.** \\
\hline Levin, Lin \& Chu t* & -4.21462 & 0.0000 \\
\hline \hline
\end{tabular}

** Probabilities are computed assuming asympotic normality

Variabel $W_{2}$

Null Hypothesis: Unit root (common unit root process)

Date: 08/19/08 Time: 23:06

Sample: 19972005

Exogenous variables: Individual effects

Automatic selection of maximum lags

Automatic selection of lags based on AIC: 0 to 1

Newey-West bandwidth selection using Bartlett kernel

Total number of observations: 31

Cross-sections included: 4 


\begin{tabular}{lcc} 
Method & Statistic & Prob. $^{* *}$ \\
\hline Levin, Lin \& Chu t* & -1.16678 & 0.1216 \\
\hline \hline
\end{tabular}

** Probabilities are computed assuming asympotic normality

Null Hypothesis: Unit root (common unit root process)

Date: 08/19/08 Time: 23:06

Sample: 19972005

Exogenous variables: Individual effects

Automatic selection of maximum lags

Automatic selection of lags based on AIC: 0 to 1

Newey-West bandwidth selection using Bartlett kernel

Total number of observations: 25

Cross-sections included: 4

\begin{tabular}{lcc}
\hline \hline & & \\
Method & Statistic & Prob.** \\
\hline Levin, Lin \& Chu t* & -2.17453 & 0.0148 \\
& & \\
\hline \hline
\end{tabular}

** Probabilities are computed assuming asympotic normality

\section{Variabel $Y$}

Null Hypothesis: Unit root (common unit root process)

Date: 08/19/08 Time: 23:08

Sample: 19972005

Exogenous variables: Individual effects

Automatic selection of maximum lags

Automatic selection of lags based on AIC: 0 to 1

Newey-West bandwidth selection using Bartlett kernel

Total number of observations: 29

Cross-sections included: 4

\begin{tabular}{lcc}
\hline \hline Method & Statistic & Prob. $^{* *}$ \\
\hline Levin, Lin \& Chu t* & 5.17693 & 1.0000 \\
\hline \hline
\end{tabular}

** Probabilities are computed assuming asympotic normality

Null Hypothesis: Unit root (common unit root process)

Date: 08/19/08 Time: 23:08

Sample: 19972005

Exogenous variables: Individual effects

Automatic selection of maximum lags

Automatic selection of lags based on AIC: 0 to 1

Newey-West bandwidth selection using Bartlett kernel

Total number of observations: 27

Cross-sections included: 4

\begin{tabular}{llc}
\hline \hline Method & Statistic & Prob.** \\
\hline Levin, Lin \& Chu t* & -6.39253 & 0.0000 \\
& & \\
\hline \hline
\end{tabular}

\footnotetext{
** Probabilities are computed assuming asympotic normality
} 
Variabel $K L$

Null Hypothesis: Unit root (common unit root process)

Date: 08/19/08 Time: 23:09

Sample: 19972005

Exogenous variables: Individual effects

Automatic selection of maximum lags

Automatic selection of lags based on AIC: 0 to 1

Newey-West bandwidth selection using Bartlett kernel

Total number of observations: 30

Cross-sections included: 4

\begin{tabular}{llc} 
Method & Statistic & Prob.** \\
\hline Levin, Lin \& Chu t* & 2.06046 & 0.9803 \\
\hline \hline
\end{tabular}

** Probabilities are computed assuming asympotic normality

Null Hypothesis: Unit root (common unit root process)

Date: 08/19/08 Time: 23:11

Sample: 19972005

Exogenous variables: Individual effects

User specified maximum lags

Automatic selection of lags based on AIC: 0

Newey-West bandwidth selection using Bartlett kernel

Total (balanced) observations: 28

Cross-sections included: 4

\begin{tabular}{lcc}
\hline \hline Method & Statistic & Prob. $^{* *}$ \\
\hline Levin, Lin \& Chu t* & -3.14691 & 0.0008 \\
\hline \hline
\end{tabular}

** Probabilities are computed assuming asympotic normality

\section{LAMPIRAN 2}

Uji Kointegrasi Pedroni

Model Upah Pokok Nominal

RESULTS:

\begin{tabular}{|c|c|c|}
\hline panel v-stat & $=$ & -0.99108 \\
\hline panel rho-stat & $=$ & 1.36253 \\
\hline panel pp-stat & $=$ & -3.13348 \\
\hline panel adf-stat & $=$ & -3.05875 \\
\hline group rho-stat & $=$ & 2.07220 \\
\hline group pp-stat & $=$ & -4.54923 \\
\hline group adf-stat & $=$ & -3.22900 \\
\hline
\end{tabular}

Nsecs $=4$, Tperiods $=9$, no. regressors $=2$

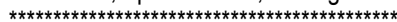




\section{Model Upah Lembur}

\section{RESULTS:}

$\begin{array}{lc}* * * * * * * * * * * * * * * * * * * * * * * * * * * * * * * * * * * * * * * * * * * * \\ \text { panel v-stat }= & -1.21465 \\ \text { panel rho-stat }= & 0.62144 \\ \text { panel pp-stat }= & -4.60428 \\ \text { panel adf-stat }= & -6.43069 \\ & \\ \text { group rho-stat }= & 1.65472 \\ \text { group pp-stat }= & -4.05115 \\ \text { group adf-stat }= & -18.14266\end{array}$

Nsecs $=4$, Tperiods $=9$, no. regressors $=2$

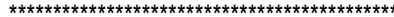

\section{LAMPIRAN 3}

\section{Penentuan Panjang Lag}

VAR Lag Order Selection Criteria Endogenous variables: W1 Y KL Exogenous variables: $\mathrm{C}$

Date: 08/19/08 Time: 22:59

Sample: 19972005

Included observations: 24

\begin{tabular}{ccclc}
\hline \hline Lag & LogL & LR & FPE & AIC \\
\hline \hline & & & & \\
\hline 0 & -565.6112 & NA & $7.61 \mathrm{e}+16$ & 47.38427 \\
1 & -477.9826 & 146.0477 & $1.10 \mathrm{e}+14$ & 40.83188 \\
2 & -459.5361 & 26.13246 & $5.21 \mathrm{e}+13$ & 40.04468 \\
3 & -434.5672 & $29.13048^{*}$ & $1.54 \mathrm{e}+13^{\star}$ & $38.71393^{*}$ \\
\hline \hline
\end{tabular}

* indicates lag order selected by the criterion

LR: sequential modified LR test statistic (each test at 5\% level)

FPE: Final prediction error

AIC: Akaike information criterion

SC: Schwarz information criterion

HQ: Hannan-Quinn information criterion

VAR Lag Order Selection Criteria

Endogenous variables: W2 Y KL

Exogenous variables: $\mathrm{C}$

Date: 08/19/08 Time: 23:00

Sample: 19972005

Included observations: 24

\begin{tabular}{lllll}
\hline \hline Lag & LogL & LPE & AIC \\
\hline \hline
\end{tabular}


$-564.7216$

$-491.5610$

$-470.9052$

$-452.5546$

\section{NA}

121.9344

29.26242

$21.40897^{*}$
$7.07 e+16$

$3.40 \mathrm{e}+14$

$1.34 \mathrm{e}+14$

$6.87 \mathrm{e}+13^{*}$
47.31014

41.96342

40.99210

$40.21289 *$

* indicates lag order selected by the criterion

LR: sequential modified LR test statistic (each test at 5\% level)

FPE: Final prediction error

AIC: Akaike information criterion

SC: Schwarz information criterion

HQ: Hannan-Quinn information criterion

\section{LAMPIRAN 4}

\section{Hasil Estimasi}

\section{Model Upah Pokok Nominal}

Redundant Variables: DW12 DY2 DUMDY2 DY DUMDY DKL3 DKL1 DY3 DUMDY3

Test Equation:

Dependent Variable: DW1

Method: Panel EGLS (Cross-section weights)

Date: 08/17/08 Time: 13:19

Sample: 20012005

Cross-sections included: 4

Total panel (balanced) observations: 20

Use pre-specified GLS weights

White period standard errors \& covariance (d.f. corrected)

\begin{tabular}{crrrr}
\hline \hline Variable & Coefficient & Std. Error & t-Statistic & Prob. \\
& & & & \\
\hline \hline C & 342.0471 & 60.76223 & 5.629271 & 0.0002 \\
DW11 & 0.000223 & $5.12 \mathrm{E}-05$ & 4.347972 & 0.0014 \\
DW13 & 0.975909 & 0.265244 & 3.679291 & 0.0043 \\
DY1 & 9.315776 & 1.430111 & 6.514022 & 0.0001 \\
DUMDY1 & -6.198307 & 1.919362 & -3.229358 & 0.0090 \\
DKL & 5.311879 & 1.175509 & 4.518789 & 0.0011 \\
ECT1 & -0.000877 & $9.66 \mathrm{E}-05$ & -9.072809 & 0.0000 \\
& & & & \\
\hline \hline
\end{tabular}

Effects Specification 
Weighted Statistics

\begin{tabular}{lrll}
\hline \hline & & & \\
R-squared & 0.914366 & Mean dependent var & 108.7092 \\
Adjusted R-squared & 0.837295 & S.D. dependent var & 220.9198 \\
S.E. of regression & 90.43766 & Akaike info criterion & 6.943250 \\
Sum squared resid & 81789.70 & Schwarz criterion & 7.441117 \\
Log likelihood & -59.43250 & F-statistic & 11.86394 \\
Durbin-Watson stat & 2.286211 & Prob(F-statistic) & 0.000304 \\
& & & \\
\hline \hline
\end{tabular}

Unweighted Statistics

\begin{tabular}{llll}
\hline \hline & & & \\
R-squared & 0.920069 & Mean dependent var & 79.30325 \\
Sum squared resid & 76341.99 & Durbin-Watson stat & 2.349822 \\
& & & \\
\hline \hline
\end{tabular}

\section{Model Upah Lembur}
Redundant Variables: DY3 DUMDY3 DY DUMDY DY2 DUMDY2 DW21 DW23 DKL2 DKL

\begin{tabular}{llll}
\hline \hline & & & \\
F-statistic & 3.412590 & Prob. F(10,4) & 0.124070 \\
Log likelihood ratio & 45.09199 & Prob. Chi-Square(10) & 0.000002 \\
& & & \\
\hline \hline
\end{tabular}

Test Equation:

Dependent Variable: DW2

Method: Panel Least Squares

Date: 08/19/08 Time: 11:28

Sample: 20012005

Cross-sections included: 4

Total panel (balanced) observations: 20

Period SUR (PCSE) standard errors \& covariance (d.f. corrected)

\begin{tabular}{|c|c|c|c|c|}
\hline Variable & Coefficient & Std. Error & t-Statistic & Prob. \\
\hline C & 186.3719 & 63.96627 & 2.913596 & 0.0113 \\
\hline DW22 & 0.000126 & 0.000644 & 0.195966 & 0.8475 \\
\hline DY1 & 17.95929 & 8.190610 & 2.192668 & 0.0457 \\
\hline DUMDY1 & -13.86867 & 9.060142 & -1.530734 & 0.1481 \\
\hline DKL1 & 0.899940 & 5.943051 & 0.151427 & 0.8818 \\
\hline ЕСТ2 & -0.002029 & 0.000632 & -3.209345 & 0.0063 \\
\hline R-squared & 0.589143 & Mean dependent var & & 36.69755 \\
\hline Adjusted R-squared & 0.442408 & S.D. dependent var & & 169.2775 \\
\hline S.E. of regression & 126.4030 & Akaike info criterion & & 12.76015 \\
\hline Sum squared resid & 223688.0 & Schwarz criterion & & 13.05887 \\
\hline Log likelihood & -121.6015 & F-statistic & & 4.015020 \\
\hline Durbin-Watson stat & 2.228035 & Prob(F-statistic) & & 0.018070 \\
\hline
\end{tabular}

